\title{
Actos Now for the prevention of diabetes (ACT NOW) study
} Ralph A DeFronzo*1, MaryAnn Banerji ${ }^{2}$, George A Bray ${ }^{3}$, Thomas A Buchanan ${ }^{4}$, Stephen Clement ${ }^{5}$, Robert R Henry ${ }^{6}$, Abbas E Kitabchi ${ }^{7}$, Sunder Mudaliar ${ }^{6}$, Nicolas Musi ${ }^{1}$, Robert Ratner ${ }^{8}$, Peter D Reaven ${ }^{9}$, Dawn Schwenke ${ }^{9}$, Frankie B Stentz ${ }^{7}$ and Devjit Tripathy ${ }^{1}$

\begin{abstract}
Address: ${ }^{1}$ Texas Diabetes Institute and University of Texas Health Science Center, San Antonio, TX, USA, ${ }^{2}$ Suny Health Science Center at Brooklyn Brooklyn, NY, USA, ${ }^{3}$ Pennington Biomedical Research Center/LSU, Baton Rouge, LA, USA, ${ }^{4}$ University of Southern California Keck School of Medicine, Los Angeles, CA, USA, ${ }^{5}$ Division of Endocrinology \& Metabolism, Georgetown University, Washington, DC, USA, ${ }^{6}$ VA San Diego Healthcare System and University of California at San Diego, USA, ${ }^{7}$ University of Tennessee, Division of Endocrinology, Diabetes and Metabolism, Memphis, TN, USA, ${ }^{8}$ Medstar Research Institute, Hyattsville, MD, USA and ${ }^{9}$ Phoenix VA Health Care System, Phoenix, AZ and W.P. Carey School of Business, Arizona State University, Tempe, AZ, USA

Email: Ralph A DeFronzo* - albarado@uthscsa.edu; MaryAnn Banerji - MaryAnn.Banerji@downstate.edu; George A Bray - brayga@pbrc.edu; Thomas A Buchanan - buchanan@usc.edu; Stephen Clement - clements@gunet.georgetown.edu; Robert R Henry - rrhenry@vapop.ucsd.edu; Abbas E Kitabchi - akitabch@utmem.edu; Sunder Mudaliar - smudaliar@vapop.ucsd.edu; Nicolas Musi - musi@uthscsa.edu; Robert Ratner - ratnermri@aol.com; Peter D Reaven - peter.reaven@va.gov; Dawn Schwenke - Dawn.Schwenke@va.gov; Frankie B Stentz - fstentz@utmem.edu; Devjit Tripathy - tripathy@uthscsa.edu

* Corresponding author
\end{abstract}

Published: 29 July 2009

BMC Endocrine Disorders 2009, 9:17 doi:10.1186/1472-6823-9-17

This article is available from: http://www.biomedcentral.com/1472-6823/9/17

(C) 2009 DeFronzo et al; licensee BioMed Central Ltd.

This is an Open Access article distributed under the terms of the Creative Commons Attribution License (http://creativecommons.org/licenses/by/2.0), which permits unrestricted use, distribution, and reproduction in any medium, provided the original work is properly cited.
Received: 13 November 2008

Accepted: 29 July 2009

\begin{abstract}
Background: Impaired glucose tolerance (IGT) is a prediabetic state. If IGT can be prevented from progressing to overt diabetes, hyperglycemia-related complications can be avoided. The purpose of the present study was to examine whether pioglitazone (ACTOS ${ }^{\circledR}$ ) can prevent progression of IGT to type 2 diabetes mellitus (T2DM) in a prospective randomized, double blind, placebo controlled trial.
\end{abstract}

Methods/Design: 602 IGT subjects were identified with OGTT (2-hour plasma glucose $=$ |40$199 \mathrm{mg} / \mathrm{dl}$ ). In addition, IGT subjects were required to have FPG $=95-125 \mathrm{mg} / \mathrm{dl}$ and at least one other high risk characteristic. Prior to randomization all subjects had measurement of ankle-arm blood pressure, systolic/diastolic blood pressure, $\mathrm{HbA}_{\mathrm{IC}}$, lipid profile and a subset had frequently sampled intravenous glucose tolerance test (FSIVGTT), DEXA, and ultrasound determination of carotid intima-media thickness (IMT). Following this, subjects were randomized to receive pioglitazone (45 mg/day) or placebo, and returned every 2-3 months for FPG determination and annually for OGTT. Repeat carotid IMT measurement was performed at 18 months and study end. Recruitment took place over 24 months, and subjects were followed for an additional 24 months. At study end (48 months) or at time of diagnosis of diabetes the OGTT, FSIVGTT, DEXA, carotid IMT, and all other measurements were repeated.

Primary endpoint is conversion of IGT to T2DM based upon FPG $\geq 126$ or 2-hour PG $\geq 200 \mathrm{mg} /$ dl. Secondary endpoints include whether pioglitazone can: (i) improve glycemic control (ii) enhance insulin sensitivity, (iii) augment beta cell function, (iv) improve risk factors for cardiovascular 
disease, (v) cause regression/slow progression of carotid IMT, (vi) revert newly diagnosed diabetes to normal glucose tolerance.

Conclusion: ACT NOW is designed to determine if pioglitazone can prevent/delay progression to diabetes in high risk IGT subjects, and to define the mechanisms (improved insulin sensitivity and/or enhanced beta cell function) via which pioglitazone exerts its beneficial effect on glucose metabolism to prevent/delay onset of T2DM.

Trial Registration: clinical trials.gov identifier: NCT0022096I

\section{Background}

Type 2 diabetes mellitus (T2DM) affects 21 million Americans [1] and approximately 194 million individuals world wide [2] and its prevalence is rapidly increasing [3]. Microvascular [4] and macrovascular [5] complications are common in T2DM and both are strongly related to the severity and duration of hyperglycemia [6-8]. The estimated cost for the treatment of T2DM and related complications in year 2007 was 174 billion dollars [9].

The natural history of T2DM has been well defined [10$14]$, starting with a genetic predisposition and progression from normal glucose tolerance with insulin resistance to impaired glucose tolerance with superimposition of beta cell failure on insulin resistance, and eventually to overt T2DM characterized by severe beta cell failure and insulin resistance.

Because of the central role that hyperglycemia plays in the development of both micro- and macrovascular complications [4-8], it follows that interventions designed to prevent or delay the onset of hyperglycemia would be effective in preventing these long term complications. Recent studies have demonstrated that life style modification $[15,16]$ and therapy with metformin [16] and thiazolidinediones $[14,17,18]$ can prevent or delay the onset of T2DM in high risk subjects. Individuals with impaired glucose tolerance (IGT) represent a high risk group, with a conversion rate that varies from $3-13 \%$ per year, depending upon the ethnic group [19].

Individuals with IGT are characterized by defects in both insulin secretion and insulin sensitivity [20-22]. Therefore, interventions designed to enhance beta cell function and ameliorate insulin resistance would be expected to be effective in preventing the progression of IGT to T2DM. Pioglitazone and other thiazolidinediones have been shown both to enhance muscle/hepatic/adipocyte insulin sensitivity [23-26] and to improve beta cell function $[16,18,27,28]$. Because thiazolidinediones reverse the characteristic defects present in IGT and T2DM, they represent a logical choice to prevent/delay the onset of diabetes in high risk individuals.

\section{Methods/Design \\ Primary Objective}

The primary purpose is to examine whether treatment of individuals with IGT with pioglitazone can prevent or delay the development of T2DM.

\section{Secondary Objectives}

Secondary objectives include whether pioglitazone can: (i) improve glycemic control; (ii) enhance insulin sensitivity; (iii) improve beta cell function; (iv) improve risk factors for cardiovascular disease; (v) cause regression/ slow progression of carotid intima-media thickness, (vi) decrease microalbuminura; (vii) revert newly diagnosed type 2 diabetic subjects to a state of normal glucose tolerance.

\section{Overall Study Design/Subject Eligibility}

The study is a prospective, randomized, double-blind placebo controlled trial to examine the efficacy of pioglitazone in reducing the incidence of T2DM in adults $(\geq 18$ years) with IGT, as defined by a 2-hour plasma glucose concentration of 140-199 mg/dl during a single OGTT [29].

In addition, all IGT subjects must have a fasting plasma glucose of $95-125 \mathrm{mg} / \mathrm{dl}$ and at least one of the following: (i) one or more components of the insulin resistance syndrome (low HDL cholesterol [ $<40 \mathrm{mg} / \mathrm{dl}$ in females; $<35$ $\mathrm{mg} / \mathrm{dl}$ in males], fasting plasma triglyceride $\geq 150 \mathrm{mg} / \mathrm{dl}$, sitting blood pressure $>135 / 85 \mathrm{mmHg}$ or on active therapy for hypertension, BMI $\geq 25 \mathrm{~kg} / \mathrm{m}^{2}\left[\mathrm{BMI} \geq 22 \mathrm{~kg} / \mathrm{m}^{2}\right.$ for Asian Americans], waist circumference $>102 \mathrm{~cm}$ in men and $>88 \mathrm{~cm}$ in women [ $>90 \mathrm{~cm}$ in Asian American men and $>80 \mathrm{~cm}$ in Asian American women]), (ii) family history of type 2 diabetes mellitus ( $\geq 1$ first degree relatives); (iii) history of gestational diabetes mellitus; (iv) polycystic ovarian syndrome; (v) minority ethnic background (Mexican American, African American, Asian, Pacific Islander, Native American). The inclusion criteria included: (i) men and women $\geq 18$ years of age, (ii) all ethnic groups, (iii) IGT with FPG $=95-125 \mathrm{mg} / \mathrm{dl}$ plus at least one high risk characteristic; IGT is defined as a 2hour plasma glucose $=140-199 \mathrm{mg} / \mathrm{dl}$ during a single 75 
gram OGTT; (iv) BMI $\geq 25 \mathrm{~kg} / \mathrm{m}^{2}$ (no upper limit) (BMI > 22 for Asian Americans). Exclusion criteria are presented in the Table 1.
During the course of recruitment, the investigators agreed to modify the glycemic inclusion criteria to allow enrollment of persons with fasting glucose of $90-125 \mathrm{mg} / \mathrm{dl}$ as

Table I: Inclusion/Exclusion Criteria.

\author{
- I. Inclusion Criteria \\ - Men and women \\ - All ethnic groups \\ $\cdot \geq 18$ years of age \\ - IGT with a FPG = 95- $125 \mathrm{mg} / \mathrm{dl}$ plus at least one additional high risk \\ - characteristic (see text). IGT is defined as a two hour plasma glucose \\ - concentration $=140-199 \mathrm{mg} / \mathrm{dl}$ during a single 75 gram OGTT. \\ - $\mathrm{BMI} \geq 25 \mathrm{~kg} / \mathrm{m}^{2}$ (no upper limit) (BMI $>22 \mathrm{~kg} / \mathrm{m}^{2}$ for Asian Americans)
}

\title{
I. Exclusion Criteria
}

- Subjects with diabetes mellitus: FPG $\geq 126 \mathrm{mg} / \mathrm{dl}$ or 2-hour plasma glucose $\geq 200 \mathrm{mg} / \mathrm{dl}$ during OGTT.

- Subjects previously treated with a thiazolidinedione (ever) or metformin (within one year prior to randomization)

- Subjects previously treated with a sulfonylurea, a meglitinide, an alpha glucosidase inhibitor for more than one week within the last year, or within the 3 months prior to randomization

- Subjects previously treated with insulin (other than during pregnancy) for more than one week within the last year or within the 3 months prior randomization.

- Medical conditions likely to limit life span and/or increase risk of intervention

- Cardiovascular disease

- Hospitalization for treatment of heart disease or stroke in past 6 months

- New York Heart Association Functional Class > 2

- Left bundle branch block or third degree AV block

- Aortic stenosis

- Systolic blood pressure > $180 \mathrm{mmHg}$ or diastolic blood pressure > $105 \mathrm{mmHg}$; subjects can be re-screened after treatment of their hypertension

- Renal disease (creatine $\geq 1.6 \mathrm{mg} / \mathrm{dl}$ for men or $\geq 1.5 \mathrm{mg} / \mathrm{dl}$ for women, or urine protein $\geq 2+$ )

- Anemia (hematocrit $<33 \%$ in men and $<30 \%$ in women); if the hematocrit increases above these levels at a later date, they can be included in the study

- Hepatitis, based on history and/or serum ALT greater than 2.5 times the upper limit of normal

- Other gastrointestinal disease (pancreatitis, inflammatory bowel disease)

- Recent or significant abdominal surgery

- Pulmonary disease with dependence on oxygen or daily use of bronchodilators

- Chronic infection (e.g., HIV, active tuberculosis)

- Conditions or behaviors likely to affect conduct of the trial

- Unwilling to accept treatment assignment by randomization

- Participation in another intervention research project that might interfere with completion of the study

- Weight loss of > 10\% in past 6 months for any reason except postpartum weight loss

- Currently pregnant or within 3 months postpartum

- Currently nursing or within 6 weeks of having completed nursing

- Pregnancy anticipated during the course of the trial

- Unwilling to undergo pregnancy testing or report possible pregnancy promptly

- Unwilling to take precautions to avoid pregnancy if potentially fertile

- Major psychiatric disorders

- Excessive alcohol intake, either acute or chronic

- Medications and medical conditions likely to confound the assessment for diabetes, including:

Thiazide diuretics at a dose greater than $25 \mathrm{mg} /$ day

Non-cardioselective beta-blockers

(individuals receiving treatment with a statin or fenofibrate will not be excluded as long as the dose has been stable for 3 months prior to randomization)

Glucocorticoids, systemic

Prescription weight-loss or weight-gain medications

- Thyroid disease, suboptimally treated as indicated by abnormal serum thyroid-stimulating hormone

- Other endocrine disorders (e.g. Cushing's syndrome, acromegaly)

- Fasting plasma triglyceride $>400 \mathrm{mg} / \mathrm{dl}$, despite treatment

- Individuals with a history of bladder cancer

- Individuals with hematuria at screening. However, subjects with hematuria may be randomized if the cause of the hematuria is found, treated, and thought unlikely to recur. 
long as the 2-hour plasma glucose concentration was $170-199 \mathrm{mg} / \mathrm{dl}$, in recognition of the high risk of diabetes in such persons.

Eight centers took part in the study and the protocol was approved by the individual IRB of the 8 participating centers. After ascertaining eligibility and collection of baseline measures as described below, subjects were randomized by center and gender using block randomization to ensure equal distribution. Prior to randomization all subjects met with a dietician and received 30 minutes of instruction consistent with the goals of the Diabetes Prevention Program [16]. These goals emphasized reduced total caloric intake, decreased fat intake, and walking $30 \mathrm{~min}$ utes per day for 4-5 days per week. Goals were reinforced on all follow up visits.

Potentially eligible IGT subjects $(n=1850)$ were identified according to recruitment procedures most suited to each of the 8 participating centers and their written, voluntary informed consent was obtained. Subjects then received a 75 gram oral glucose tolerance test (OGTT) with samples drawn at $-30,-15,0$, and every 15 minutes thereafter for 2 hours for determination of plasma glucose, insulin, C-peptide, and free fatty acid concentrations. The OGTT was performed at $0800 \mathrm{~h}$ following an overnight fast (after $2000 \mathrm{~h}$ ). Samples for determination of plasma glucose concentration were sent to the Central Laboratory (Texas Diabetes Institute, San Antonio, TX) and sites were notified about subject eligibility (FPG $\geq 95$ $\mathrm{mg} / \mathrm{dl}$ and 2-h PG $=140-199 \mathrm{mg} / \mathrm{dl}$ ) within 48 hours. Subjects meeting these criteria returned for a medical history, physical examination, screening blood tests (chemistries and complete blood cell count), urinalysis, and electrocardiogram. During this visit or on a subsequent visit prior to randomization, a fasting blood sample was obtained for the measurement of $\mathrm{HbA}_{1 c^{\prime}}$ and lipid profile, and plasma and serum were collected for later measurement of novel risk factors. The first voided morning urine specimen was collected for determination of microalbumin to creatinine ratio and a 24-hour urine was collected for determination of 8-epi-prostaglandin $\mathrm{F}_{2} \alpha$ (also termed $15-\mathrm{F}_{2 \mathrm{t}}$-IsoP), a measure of oxidative stress [30]. Systolic and diastolic blood pressures were measured with an automated Dinamap Pro 100 instrument (GE Medical Systems, Milwaukee, WI) following 5 minutes in the reclining position and after 5 minutes in the upright position. Ankle-arm blood pressure was measured as described by Papamichael et al [31].

Body composition was assessed by measurement of body weight (to the nearest $0.1 \mathrm{~kg}$ ) on a digital scale (Health-OMeter, Bridgeview, IL) and height (to the nearest $0.1 \mathrm{~cm}$ ). Waist circumference was measured using the Gulick II Tape Measure, model \#67010 (Gays Mills, WI) at the mid- point between the highest point at the iliac crest and the lowest part of the costal margin in the midaxillary line. Waist circumference was measured in the morning in the erect position after voiding and following an overnight fast. Percent body fat and lean body mass were determined by DEXA using the 4500A Hologic (Bedford, MA) in 4 of the 8 centers. For quality assurance, a Spine Phantom (Hologic) was scanned every morning and a Step Phantom (Hologic) was scanned every week. Standardization and cross-validation of the DEXA measurement between the 4 participating centers was achieved by performing 5 consecutive (once daily) measurements using the same Whole Body Phantom (Hologic) which circulated between all sites. Whole Body Phantom measurements were performed at all sites yearly, for 4 consecutive years. The percent body fat and lean body mass coefficients of variation within a given center were $0.8-1.5 \%$ and $0.7-1.5 \%$ (depending on the site), respectively. The percent body fat and lean body mass coefficients of variation between centers were $3.7 \%$ and $6.0 \%$, respectively. The percent body fat and lean body mass coefficients of variation between the yearly scans were $0.6 \%$ and $0.9 \%$, respectively.

Within 3-10 days after the OGTT, subjects at 4 centers were asked to return for a FSIVGTT [32], which was performed at $0800 \mathrm{~h}$ following an overnight fast (after 2000 h). A catheter was inserted into an antecubital vein and 3 baseline arterialized blood samples (heated box to $70^{\circ} \mathrm{C}$ ) were obtained. At time zero glucose $(300 \mathrm{mg} / \mathrm{kg})$ was given as a smooth intravenous bolus over one minute. Insulin ( 0.03 units $/ \mathrm{kg}$ ) was given as an intravenous bolus 20 minutes after the start of the glucose injection. Over the 240 minutes following glucose ingestion, 22 blood samples were drawn at 2,3,4,5,6,8,10,14,19,22,24,27,30,40,50,70,90,

$120,150,180,210$, and 240 minutes for determination of plasma glucose and insulin concentrations.

At $8 \mathrm{AM}$ on a separate day subjects from seven centers had a measurement of carotid intimal media thickness (IMT) using B-mode ultrasound (Logiq, GE Medical Systems, Milwaukee, WI) [33]. A standardized protocol was followed by all centers to assure quality control. Prior to initiation of the study, all ultrasound technologists received training at the coordinating center, directed by Dr. Howard Hodis at the University of Southern California, to ensure uniformity of measurement amongst centers. Acquisition of an image of the far wall of the common carotid was obtained and carotid IMT scans were sent to the coordinating center, where they were read blindly by two readers, as previously described [33]. In a subset of subjects at 7 of the 8 centers a second measurement was performed within 2 weeks of the initial scan to determine reproducibility and technologist performance. The coeffi- 
cient of variation of these two measurements was $0.72 \%$ (range $=0.14-0.90)$. Carotid IMT measurements also were performed at mid study and at study end (or at time of diagnosis of diabetes) to examine the rate of change in carotid IMT.

\section{Recruitment and Following Visits}

The first IGT subject was recruited in January of 2004 and enrollment was completed $(n=602)$ on February 13, 2006. All subjects were followed until they dropped out, reached the primary endpoint of diabetes, or reached the end of the blinded phase of the study 2 years from the time of recruitment of the last subject, at which time (February of 2008) all baseline measurements/procedures were repeated.

Following completion of the baseline studies, IGT subjects were randomized to receive pioglitazone, $30 \mathrm{mg} / \mathrm{day}$, or placebo and returned 1 month later. If no adverse events were present, the dose of blinded pioglitazone (and placebo) was increased to $45 \mathrm{mg} /$ day (maximum dose) and participants returned for follow-up visits at $2,4,6,8,10$, and 12 months during the first year and every 3 months subsequently. On each visit a brief physical exam was performed, including measurement of weight, blood pressure, and pulse and the presence or absence of edema was recorded and graded at each visit, as was information for subjective assessment of medication side effects (excessive weight gain, edema, other). An interim medical history with a detailed cardiovascular questionnaire was obtained. Blood for determination of fasting plasma glucose concentration AST and ALT, a urine pregnancy test, and measurement of waist circumference were obtained on each follow up visit. Serum chemistries, CBC, and urine dipstick for hematuria was performed on each 6 month visit after randomization. $\mathrm{HbA}_{1 \mathrm{c}}$ was measured every 12 months and the OGTT was repeated every 12 months. Blood for measurement of C-reactive protein, adipocytkines, markers of inflammation and other atherosclerotic cardiovascular risk factors was obtained on the final visit while on active treatment, i.e. 2 years after the last subject was enrolled, or at the time of diagnosis of diabetes. An EKG, DEXA, urine for microalbumin/creatinine ratio and $15-\mathrm{F}_{2 \mathrm{t}}$-IsoP also were obtained on this final visit. Carotid IMT was measured 15-18 months after randomization and again at the final visit while on active treatment. The FSIVGTT was repeated on this final visit at centers participating in the FSIVGTT substudy.

\section{Conversion of IGT to Diabetes}

Conversion of IGT to diabetes was made by ADA criteria [29]: (i) FPG $\geq 126 \mathrm{mg} / \mathrm{dl}$ or (ii) $2-\mathrm{h}$ PG during OGTT $\geq$ $200 \mathrm{mg} / \mathrm{dl}$. In either case, the diagnosis of diabetes was confirmed by an OGTT, whether the initial diagnosis was made by a FPG $\geq 126 \mathrm{mg} / \mathrm{dl}$ (i.e., on a 2-3 month follow up visit or on an annual follow up visit) or with a 2-h PG $\geq 200 \mathrm{mg} / \mathrm{dl}$ during the annual OGTT. If the repeat measurement confirmed the diagnosis of diabetes, the primary endpoint was met and a FSIVGTT/carotid IMT measurement/final visit blood draws were obtained. Any IGT subject who developed type 2 diabetes (pioglitazone-treated or placebo groups) was started on open label pioglitazone (30 mg/day and titrated to $45 \mathrm{mg} /$ day [maximum dose] after one month), but the randomization code was not broken. These converters continued with all scheduled follow up visits/procedures until the study was completed (February of 2008). If the $\mathrm{HbA}_{1 \mathrm{c}}$ or FPG increased to $\geq 8.0 \%$ or $\geq 180 \mathrm{mg} / \mathrm{dl}$, respectively, while an open label pioglitazone, the OGTT/FSIVGTT/close out visit were performed and appropriate additional antidiabetic therapy started.

A Data Safety Monitoring Board received a copy of all adverse events, as well as detailed information about body weight, edema, AST/ALT, and other medication side effects monthly. The DSMB had a teleconference every 6 months to review all safety data. All cardiovascular events and EKG documented myocardial infarctions will be reviewed by an adjudication committee.

\section{Measurements}

All analytical measurements were performed in a central laboratory at the Texas Diabetes Institute (San Antonio, TX). Plasma glucose concentration was measured by the glucose oxidase reaction (Glucose Oxidase Analyzer, Beckman Instruments, Fullerton, CA). Plasma insulin was measured by radioimmunoassay (Diagnostic Products, Los Angeles, CA). The interassay and intra-assay CVs for the insulin assay are $7.1 \%$ and $5.1 \%$, respectively. Plasma C-peptide was measured by radioimmunoassay (Diagnostic Systems, Webster, TX). The interassay and intra-assay CVs for the C-peptide assay are $2.4 \%$ and $4.3 \%$, respectively. $\mathrm{HbA}_{1 \mathrm{c}}$ was measured by an ion-exchange HPLC instrument (Bayer DCA 2000, Leverkusen, Germany). Total plasma cholesterol and triglycerides were measured using the CHOD-DAOS method (WAKO, Richmond, VA) and an enzymatic assay (Stanbio Lab, Boerne, TX). HDL cholesterol was measured after precipitation of apolipoprotein B-containing lipoproteins with dextran sulfate$\mathrm{Mg}^{++}$, using the CHOD-DAOS method (WAKO, Richmond, VA). LDL cholesterol was calculated by the Friedewald equation.

\section{Calculations}

Incremental area under the curve (AUC) for plasma glucose and insulin concentrations during the OGTT was calculated according to the trapezoidal rule. The insulinogenic index was calculated as $\Delta \mathrm{I}$ (AUC) $/ \Delta \mathrm{G}$ (AUC) from 0-30 and 0-120 minutes [21,22]. The insulin secretory rate during the OGTT was calculated by deconvolu- 
tion of the plasma C-peptide curve [34] and expressed as ISR/ $\Delta \mathrm{G}[21,22,35]$.

During the FSIVGTT, first phase insulin secretion was calculated as the increment in plasma insulin concentration (AUC) above baseline from 0-10 minutes and as the peak increment in plasma insulin concentration (minus baseline) during the 0-10 minute time period. Indices of insulin sensitivity $\left(\mathrm{S}_{\mathrm{I}}\right)$ and glucose effectiveness $\left(\mathrm{S}_{\mathrm{G}}\right)$ were determined by minimal model analysis of insulin and glucose concentrations during the FSIVGTT as previously described [32].

The insulin secretion/insulin resistance or disposition index during the OGTT was calculated as $\Delta \mathrm{I} / \Delta \mathrm{G} \times$ Matsuda index and as $\Delta \mathrm{I} / \Delta \mathrm{G} \times \mathrm{S}_{\mathrm{I}}[32,36]$. The hepatic insulin resistance index was calculated as the FPI $\times$ FPG (equivalent to inverse of HOMA) [37]. The basal adipocyte insulin resistance index was calculated as the fasting plasma insulin $($ FPI $) \times$ fasting plasma FFA concentrations [38].

\section{Statistical Analysis and Sample Size}

General Statistical Plan: Analysis of primary and secondary endpoints will utilize the intent-to-treat approach [39]. All participants will be included in their randomly assigned pioglitazone or placebo treatment groups. All statistical tests will be two-sided and require alpha $=0.05$ to be considered significant.

\section{Primary and Secondary Endpoints}

The primary endpoint is the development of diabetes mellitus according to ADA criteria [29]. Accordingly, the principal analysis will be a life-table analysis of the time from randomization to the confirmed development of diabetes. Separate life-table estimated cumulative incidence curves will be calculated for the pioglitazone-treated and placebo-treated groups, which will be compared using a logrank test $[38,40]$. Subjects who are lost to follow up or who prematurely decide to drop out of the study will be categorized according to data obtained up to their last follow-up visit.

Secondary outcomes (i.e., cardiovascular events and mortality) will be compared using the same life-table analysis described above for the primary endpoints.

Repeated measures data (i.e., FPG, 2-hour plasma glucose during OGTT, $\mathrm{HbA}_{1 c^{\prime}}$ measures of insulin secretion and insulin sensitivity, plasma lipids and other cardiovascular risk factors, blood pressure, carotid initmal media thickness, body weight and BMI, measures of fat mass and fat topography) will be compared between the pioglitazonetreated and placebo-treated groups using longitudinal data methods: (i) point prevalence of a discrete characteristic (i.e., normal or impaired glucose tolerance) at repeated visits over time [40] and (ii) multivariate rank analysis of quantitative (i.e., FPG, 2-hour plasma glucose, $\mathrm{HbA}_{1 \mathrm{c}^{\prime}}$ plasma lipids, plasma cardiovascular risk factors, etc) variables over repeated visits [40]. Differences in slopes over time (i.e., rate of change in FPG, 2-hour plasma glucose, $\mathrm{HbA}_{1 c^{\prime}}$ plasma lipids, etc) between pioglitazone-treated and placebo-treated groups will be compared by the parametric linear random effects model [41].

\section{Sample Size}

The conversion rate of IGT to diabetes varies considerably based upon ethnicity and a number of other risk factors. The DPP [42] cited 21 studies with conversion rates (percent per year) ranging from $2.3 \%$ to $11 \%$. In addition, they evaluated data sets from six population based cohorts [43]. The conversion rate from IGT to diabetes in these six studies was 5.8 per 100 person-years for followup and rose to 8.2 per 100 person-years for individuals with a fasting plasma glucose concentration $>100 \mathrm{mg} / \mathrm{dl}$. In certain ethnic groups, (i.e., Latinos with a history of GDM), much higher conversion rates of IGT to diabetes $(14.3 \%$ per year) have been reported $[18,44]$. The DPP [15] demonstrated a conversion rate of IGT to diabetes of approximately $11 \%$ per year. In the group of IGT subjects treated with diet/exercise and metformin, the conversion rates were decreased by $58 \%$ and $31 \%$, respectively. In the TRIPOD study [18], GDM women treated with placebo converted to diabetes at a rate of $12.1 \%$ per year and this rate was decreased to $5.4 \%$ in the troglitazone-treated group. Based upon this information (see assumptions below), it can be calculated that approximately 600 subjects with IGT will be required to achieve $90 \%$ statistical power that pioglitazone decreases the conversion rate of IGT to type 2 diabetes by $50 \%$. This power calculation assumes that randomized individuals drop out prior to the confirmed diagnosis of diabetes with an exponential hazard rate of 0.10 (or less) per year.

The following assumptions were used to calculate the sample size:

(i) The primary endpoint is the development of diabetes,

(ii) Participants are randomized over a 21 month period and followed for a total of 3.75 years, starting from the time that the first IGT subject is recruited,

(iii) Type I error rate (alpha) is 0.05 ,

(iv) The desired power is $90 \%$,

(v) The development of diabetes in the placebotreated group is $11 \%$ per year, 
(vi) The hazard rate for the development of diabetes in the pioglitazone-treated group is reduced by $50 \%$.

(vii) The drop out rate is $10 \%$ per year

During the course of recruitment, it became clear that the recruitment goal would not be reached in the planned 21 month period allotted for recruitment. To preserve study power, the recruitment period was lengthened 3 months to a total of 24 months to allow recruitment of the targeted number of participants with a commensurate increase in the total study duration for a follow up time of 4 years, starting from the time that the first IGT subject was recruited.

\section{Competing interests}

RAD is on the Advisory Board of Takeda, Amylin, Eli Lilly, Roche, Novartis, Johnson and Johnson, and Bristol Meyers Squibb. RAD has Grant Support from Takeda, Amylin, Eli Lilly, Roche, Novartis, BMS, Merck, and Pfizer, he is a member of the Speakers Bureau of Takeda, Eli Lilly, and Amylin, and he is a consultant for Takeda, Amylin, Eli Lilly, Roche, Novartis, ISIS and BMS. GAB is on the Advisory Board for Amylin Pharmaceuticals and has grant support from Merck. SM has Grant Support from GSK, SanofiAventis, and Intercept Pharm. RRH has grant support from Amylin, Biodel, BMS, GSK, Keryx, Lifescan, Eli Lilly, Merck, Novartis, Novo, Pfizer, Roche, Sankyo, and Veralight, he is a consultant for Amylin, Astra Zeneca, BMS, Diobex, GSK, ISIS, Eli Lilly, Merck, Novartis, Novo, Roche, Sankyo, Sanofi Aventis, and Takeda, and he is a member of the Speakers Bureau of Amylin, GSK, and Eli Lilly. NM has no conflicts of interest to declare. MAB has Research Grants from Novartis, Takeda and Pfizer, she is a consultant for BMS and Boehringer Ingleheim, and she is a speaker for Novartis, Takeda, Pfizer, Merck, and SanofiAventis. RER has grant support from AstraZenica, Bayhill Therapeutics, Boehringer Ingelheim, GSK, Merck, Pfizer, Takeda, and Veralight, he is on the Advisory Board of Amylin, AstraZenica, Eli Lilly, GSK, Lifescan, NovoNordisk, Sanofi-Aventis, Takeda, and Tethys Bioscience, and he has stock ownership in Merck, Johnson \& Johnson, and Abbott. FBS has no conflict of interest. AEK is on the Advisory Board for Merck, he is a member of the Speakers Bureau for Takeda, and he has grant support from Takeda and Sanofi-Aventis. DCS has grant support from Takeda. DT has grant support from Takeda. SC has no conflict of interest. TAB has grant support from Takeda and he is a member of the Speakers Bureau and on Advisory Board for Takeda. PDR has grant support from Takeda and Amylin/Lilly, and he is a member of the Speakers Bureau for Takeda and Merck.

\section{Authors' contributions}

The initial draft of the manuscript was prepared by RAD and all authors' reviewed the manuscript and provided their comments in writing. The revised manuscript was then again reviewed by all authors for final approval.

This study was initially designed by RAD and subsequently critiqued by all authors. The study then was submitted to Takeda Pharmaceuticals NA and funded as an investigator-initiated grant. TPNA was not involved in the study design, study performance, data analyses, or manuscript preparation. At each study site, the investigators were responsible for patient recruitment and performance of all study-related procedures. All authors read and approved the final version of the manuscript.

\section{References}

I. Cowie CC, Rust KF, Byrd-Holt DD, Eberhardt MS, Flegal KM, Engelgau MM, Saydah SH, Williams DE, Geiss LS, Gregg EW: Prevalence of diabetes and impaired fasting glucose in adults in the U.S. population: National Health And Nutrition Examination Survey 1999-2002. Diabetes Care 2006, 29:1263-1268.

2. Wild S, Roglic G, Green A, Sicree R, King H: Global prevalence of diabetes: estimates for the year 2000 and projections for 2030. Diabetes Care 2004, 27: 1047-1053.

3. World Health Organization: Diabetes Programme Facts and Figures, 2007. [http://www.who.int/diabetes/facts/en/]. World Health Organisation; Geneva, Switzerland

4. UK Prospective Diabetes Study Group: Quality of life in type 2 diabetic patients is affected by complications but not by intensive policies to improve blood glucose or blood pressure control (UKPDS 37). Diabetes Care 1999, 22: I | 25- I I 36.

5. Stratton IM, Adler AI, Neil HA, Matthews DR, Manley SE, Cull CA, Hadden D, Turner RC, Holman RR, Prospective Diabetes Study Group: Association of glycaemia with macrovascular and microvascular complications on type 2 dia betes (UKPDS 35): prospective observational study. BM/ 2000, 32I:405-4I2.

6. Intensive blood-glucose control with sulphonylureas or insulin compared with conventional treatment and risk of complications in patients with type 2 diabetes (UKPDS 33). UK Prospective Diabetes Study (UKPDS) Group. Lancet 1998:837-853.

7. Klein R, Barrett-Connor EL, Blunt BA, Wingard DL: Visual impairment and retinopathy in people with normal glucose tolerance, impaired glucose tolerance, and newly diagnosed NIDDM. Diabetes Care 1991, 14:914-918.

8. Shichiri M, Kishikawa $H$, Ohkubo $Y$, Wake N: Long-term results of the Kumamoto Study on optimal diabetes control in type 2 diabetic patients. Diabetes Care 2000, 23(Suppl 2):B2I-29.

9. American Diabetes Association: Economic costs of diabetes in the US in 2007. Diabetes Care 2008, $31: 1-20$.

10. Defronzo RA: Lilly lecture 1987. The triumvirate: beta-cell, muscle, liver. A collusion responsible for NIDDM. Diabetes 1988, 37:667-687.

II. Weyer C, Bogardus C, Mott DM, Pratley RE: The natural history of insulin secretory dysfunction and insulin resistance in the pathogenesis of type 2 diabetes mellitus. J Clin Invest 1999, 104:787-794.

12. Festa A, Williams K, D'Agostino R Jr, Wagenknecht LE, Haffner SM: The natural course of beta-cell function in nondiabetic and diabetic individuals: the Insulin Resistance Atherosclerosis Study. Diabetes 2006, 55: I | |4- I I 20.

13. Lyssenko V, Almgren P, Anevski D, Perfekt R, Lahti K, Nissen M, Isomaa B, Forsen B, Homstrom N, Saloranta C, Taskinen MR, Groop L, Tuomi T: Predictors of and longitudinal changes in insulin sensitivity and secretion preceding onset of type 2 diabetes. Diabetes 2005, 54:166-174.

14. Xiang AH, Peters RK, Kjos SL, Marroquin A, Goico J, Ochoa C, Kawakubo M, Buchanan TA: Effect of pioglitazone on pancreatic 
beta-cell function and diabetes risk in Hispanic women with prior gestational diabetes. Diabetes 2006, 55:517-522.

15. Tuomilehto J, Lindstrom J, Eriksson JG, Valle TT, Hamalainen $H$, llanne-Parikka P, Keinanen-Kiukaanniemi S, Laakso M, Louheranta A, Rastas M, Salminen V, Uusitupa M: Prevention of type 2 diabetes mellitus by changes in lifestyle among subjects with impaired glucose tolerance. N Engl J Med 200I, 344:I343-I350.

16. Knowler WC, Barrett-Connor E, Fowler SE, Hamman RF, Lachin JM, Walker EA, Nathan DM: Reduction in the incidence of type 2 diabetes with lifestyle intervention or metformin. $N$ Engl J Med 2002, 346:393-403.

17. Gerstein HC, Yusuf S, Bosch J, Pogue J, Sheridan P, Dinccag N, Hanefeld M, Hoogwerf B, Laakso M, Mohan V, Shaw J, Zinman B, Holman RR: Effect of rosiglitazone on the frequency of diabetes in patients with impaired glucose tolerance or impaired fasting glucose: a randomised controlled trial. Lancet 2006, 368:1096-1105.

18. Buchanan TA, Xiang AH, Peters RK, Kjos SL, Marroquin A, Goico J, Ochoa C, Tan S, Berkowitz K, Hodis HN, Azen SP: Preservation of pancreatic beta-cell function and prevention of type 2 diabetes by pharmacological treatment of insulin resistance in high-risk hispanic women. Diabetes 2002, 5 I:2796-2803.

19. Gillies CL, Abrams KR, Lambert PC, Cooper NJ, Sutton AJ, Hsu RT, Khunti K: Pharmacological and lifestyle interventions to prevent or delay type 2 diabetes in people with impaired glucose tolerance: systematic review and meta-analysis. BMJ 2007, 334:299-308.

20. Ferrannini E, Gastaldelli A, Miyazaki Y, Matsuda M, Mari A, DeFronzo RA: Beta cell function in subjects spanning the range from normal glucose tolerance to over diabetes: A new analysis. J Clin Endocrinol Metab 2005, 90:493-500.

21. Abdul-Ghani MA, Jenkinson CP, Richardson DK, Tripathy D, DeFronzo RA: Insulin secretion and action in subjects with impaired fasting glucose and impaired glucose tolerance: results from the Veterans Administration Genetic Epidemiology Study. Diabetes 2006, 55: 1430-I435.

22. Abdul-Ghani A, Tripathy D, DeFronzo RA: Contributions of $\beta$-cell dysfunction and insulin resistance to the pathogenesis of impaired glucose tolerance and impaired fasting glucose. Diabetes Care 2006, 29: I I30-II39.

23. Miyazaki Y, Mahankali A, Matsuda M, Glass L, Mahankali S, Ferrannini E, Cusi K, Mandarino LJ, DeFronzo RA: Improved glycemic control and enhanced insulin sensitivity in type 2 diabetic subjects treated with pioglitazone. Diabetes Care 200I, 24:710-7I9.

24. Miyazaki Y, He H, Mandarino LJ, DeFronzo RA: Rosiglitazone improves downstream insulin receptor signaling in type 2 diabetic patients. Diabetes 2003, 52:1943-1950.

25. Kim YB, Ciaraldi TP, Kong A, Kim D, Chu N, Mohideen P, Mudaliar S, Henry RR, Kahn BB: Troglitazone but not metformin restores insulin-stimulated phosphoinositide 3-kinase activity and increases pI I 0 beta protein levels in skeletal muscle of type 2 diabetic subjects. Diabetes 2002, 5 I:443-448.

26. Maggs DG, Buchanan TA, Burant CF, Cline G, Gumbiner B, Hsueh WA, Inzucchi S, Kelley D, Nolan J, Olefsky JM, Polonsky KS, Silver D, Valiquett TR, Shulman GI: Metabolic effects of troglitazone monotherapy in type 2 diabetes mellitus. A randomized, double-blind, placebo-controlled trial. Ann Intern Med 1998, I 28: 176-185.

27. Gastaldelli A, Ferrannini E, Miyazaki Y, Matsuda M, Mari A, DeFronzo RA: Thiazolidinediones improve beta-cell function in type 2 diabetic patients. Am J Physiol Endocrinol Metab 2007 292:E87|-883.

28. Kahn SE, Haffner SM, Heise MA, Herman WH, Holman RR, Jones NP, Kravitz BG, Lachin JM, O'Neill MC, Zinman B, Viberti G: Glycemic durability of rosiglitazone, metformin, or glyburide monotherapy. N Engl J Med 2006, 355:2427-2443.

29. American Diabetes Association: Diagnosis and Classification of Diabetes. Diabetes Care 2008, 31:S55-S60.

30. Roberts LJ 2nd, Morrow JD: The generation and actions of isoprostanes. Biochim Biophys Acta 1997, 1345: | 21-135.

31. Papamichael CM, Lekakis JP, Stamatelopoulos KS, Papaioannou TG, Alevizaki MK, Cimponeriu AT, Kanakakis JE, Papapanagiotou A, Kalofoutis AT, Stamatelopoulos SF: Ankle-brachial index as a predictor of the extent of coronary atherosclerosis and cardiovascular events in patients with coronary artery disease. Am J Cardiol 2000, 86:615-618.
32. Bergman RN: Toward physiologic understanding of glucose tolerance. Diabetes 1989, 38:1512-1517.

33. Hodis HN, Mack WJ, Barth J: Carotid intima-media thickness as a surrogate end point for coronary artery disease. Circulation 1996, 94:23|I-23I2.

34. Van Cauter E, Mestrez F, Sturis J, Polonsky KS: Estimation of insulin secretion rates from C-peptide levels. Comparison of individual and standard kinetic parameters for C-peptide levels. Comparison of individual and standard kinetic parameters for C-peptide clearance. Diabetes 1992, 41:368-377.

35. Gastaldelli A, Ferrannini E, Miyazaki Y, Matsuda M, DeFronzo RA: Beta cell dysfunction and glucose intolerance: Results from the San Antonio Metabolism (SAM) study. Diabetologia 2004, 47:3I-39.

36. Matsuda M, DeFronzo RA: Insulin sensitivity indices obtained from oral glucose tolerance testing: comparison with the euglycemic glucose clamp. Diabetes Care 1999, 22: | 462-I 470.

37. Mathews D, Hosker J, Rudenski A, Naylor B, Treacher D, Turner R: Homeostasis model assessment: insulin resistance and beta cell function from fasting plasma glucose and insulin concentration in man. Diabetologia 1985, 28:4I2-4I9.

38. Groop LC, Bonadonna RC, Shank M, Petrides AS, DeFronzo RA: Role of free fatty acids and insulin in determining free fatty acid and lipid oxidation in man. J Clin Invest I99I, 87:83-89.

39. Peduzzi P, Wittes J, Detre K, Holford T: Analysis as-randomized and the problem of non-adherence: an example from the Veterans Affairs Randomized Trial of Coronary Artery Bypass Surgery. Statistics in Medicine 1993, I 2: I I85-I I 95.

40. Kalbfleisch JD, Prentice RL: The Statistical Analysis of Failure Time Data. New York: John Wiley; 1980.

4I. Lachin JM, Wei LJ: Estimators and tests in the analysis of multiple nonindependent $2 \times 2$ tables with partially missing observations. Biometrics 1988, 44:5।3-528.

42. The Diabetes Prevention Program Research Group: The Diabetes Prevention Program: baseline characteristics of the randomized cohort. Diabetes Care 2000, 23:1619-1629.

43. Edelstein SL, Knowler WC, Bain RP, Andres R, Barrett-Connor EL, Dowse GK, Haffner SM, Pettitt DJ, Sorking JD, Muller DC, Collins VR, Hamman RF: Predictors of progression from impaired glucose tolerance to NIDDM: An analysis of six prospective studies. Diabetes 1997, 46:70I-7I0.

44. Azen SP, Peters RK, Berkowitz K, Kjos S, Xiang AN, Buchanan TA for the TRIPOD Study Group: TRIPOD (TRoglitazone In the Prevention Of Diabetes): A randomized, placebo-controlled trial of troglitazone in women with prior gestational diabetes mellitus. Controlled Clin Trials 1998, 19:217-231.

\section{Pre-publication history}

The pre-publication history for this paper can be accessed here:

\section{http://www.biomedcentral.com/1472-6823/9/17/prepub}

Publish with Biomed Central and every scientist can read your work free of charge

"BioMed Central will be the most significant development for disseminating the results of biomedical research in our lifetime. "

Sir Paul Nurse, Cancer Research UK

Your research papers will be:

- available free of charge to the entire biomedical community

- peer reviewed and published immediately upon acceptance

- cited in PubMed and archived on PubMed Central

- yours - you keep the copyright 